\title{
Characteristic left ventricular regional wall motion abnormality as a sign of cardiotoxicity?
}

\section{Nikša Drinković Jr* \\ University of Zagreb School of Medicine, University Hospital Centre Zagreb, Zagreb, Croatia}

RECEIVED:

April 15, 2015

ACCEPTED:

April 20, 2015

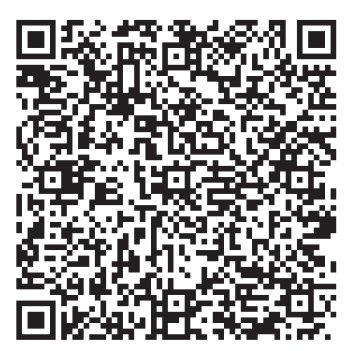

KEYWORDS: dilated cardiomyopathy, cardiotoxicity, regional wall motion.

CITATION: Cardiol Croat. 2015;10(3-4):86. | DOI: http://dx.doi.org/10.15836/ccar.2015.86

ORCID: Nikša Drinković, Jr, http://orcid.org/0000-0002-1053-5477

*ADDRESS FOR CORRESPONDENCE: Nikša Drinković, Klinički bolnički centar Zagreb, Kišpatićeva 12, HR-10000 Zagreb, Croatia. Phone: +385-1-2388-888. E-mail: ndrink@gmail.com

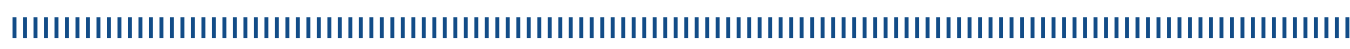

We have noticed characteristic regional wall motion pattern in dilated cardiomyopathy - inferoposterior akinesia with preserved contractility in proximal third of the posterior wall together with various degree of hypocontractility in the remaining left ventricle. ${ }^{1}$ In retrospective analysis of 30 consecutive echocardiographic examinations this pattern was present in 28 adult patients with dilated cardiomyopathy. In the remaining two, regional wall motion abnormality started with inferoposterior hypokinesis and during 3 to 4 years follow up evolved in akinesia but contractility in proximal third of the posterior wall remained preserved. We are currently investigating if this wall motion pattern can help in avoiding unnecessary coronary angiography procedures. Also it is of great interest to answer when this pattern occurs in the course of chemotherapy and is it a useful sign of early cardiotoxicity. In ongoing study we hope to answer this questions and find out what is the recovery potential if chemotherapy is stopped an cardioprotective medications instituted immediately after recognition of these simple and quickly acquirable parameters.

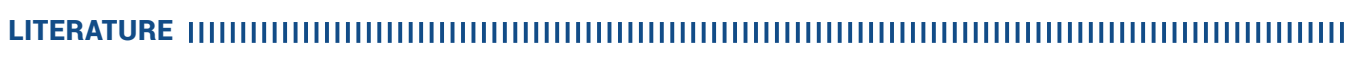

1. Drinković N Jr. Characteristic LV regional wall motion abnormality: sign of cardiotoxicity? J Am Coll Cardiol. 2015;65(7):758. DOI: http://dx.doi.org/10.1016/j.jacc.2014.10.073 